\title{
Brain-derived neurotrophic factor in the nucleus of the solitary tract modulates body composition
}

Ageing is commonly accompanied by loss muscle mass a concomitant increase in adiposity, which increases the risk of obesity. The nucleus of the solitary tract (NTS) is a brain region located in the medulla oblongata of the brainstem and has been recognized as an important modulator of homeostasis, including energy homeostasis ${ }^{(1)}$. Brain-derived neurotrophic factor (Bdnf) is a key regulator of energy balance. Both people and mice that do not produce Bdnf or a key receptor that it signals through are hyperphagic and obese. However, where Bdnf is produced to influence appetite and body weight has not been fully defined. One of the regions where Bdnf is expressed is the $\operatorname{NTS}^{(2)}$ and there we examine its function within this brain region.

In this study, Bdnf was knocked down only within the NTS in middle aged male and female mice by injecting AAV expressing the Cre recombinase (AAV-Cre) or AAV expressing mCherry protein (AAV- mCherry) into the NTS of a Bdnf flox'd mouse line via stereotaxic surgery. Viral vectors were delivered into the NTS of middle aged Bdnf floxed mice. Control group $(n=7)$ received control AAV-mCherry (WT levels of Bdnf) whereas experimental group $(n=9)$ received AAV-Cre-mCherry to selectively knockdown Bdnf only in the NTS. Eight weeks later, energy intake and physical activity were assessed through metabolic cages (TSE Phenomaster), whereas body composition was assessed via Echo MRI. All data in brackets are presented as mean values of Control vs. Bdnf knockdown respectively.

Knockdown of Bdnf only in the NTS significantly increased lean mass $(29.54 \mathrm{~g}$ vs. $26.38 \mathrm{~g} ; \mathrm{p}=0.0040 ; 95 \% \mathrm{CI}=1.201$ to 5.124$)$ and energy intake $(4.36 \mathrm{~g}$ vs. $5.39 \mathrm{~g} ; \mathrm{p}<0.0001 ; 95 \% \mathrm{CI}=0.6625$ to 1.409$)$.

This change in body composition occurred despite lower levels of physical activity (11961 counts vs. 20093 counts; $p=0.0003 ; 95 \%$ $\mathrm{CI}=3940$ to 12324) in Bndf NTS knockdown mice. Knockdown of Bdnf in the NTS significantly also resulted in improved glucose handling and clearance at $15 \mathrm{mins}(29.42 \mathrm{mmol} / 1 \mathrm{vs}$. $22.18 \mathrm{mmol} / 1 ; \mathrm{p}=0.0178 ; 95 \% \mathrm{CI}=13$ to 1.474$), 90 \mathrm{mins}(13.70 \mathrm{mmol} / 1 \mathrm{vs}$.

$11.03 \mathrm{mmol} / \mathrm{l} ; \mathrm{p}=0.0431 ; 95 \% \mathrm{CI}=13.70$ to 11.03$)$ and $120 \mathrm{~min}$ post glucose treatment $(\mathrm{p}=0.0165 ; 95 \% \mathrm{CI}=4.086$ to 0.4915$)$. Similarly, Bndf NTS knockdown mice were more insulin sensitive, as indicated with an insulin tolerance test at 30 mins (8.840mmol/1 vs. $6.614 \mathrm{mmol} / 1 ; \mathrm{p}=0.0432 ; 95 \% \mathrm{CI}=4.370$ to 0.08191$), 45 \mathrm{mins}(6.620 \mathrm{mmol} / 1$ vs. $5.700 \mathrm{mmol} / \mathrm{l} ; \mathrm{p}=0.0063 ; 95 \% \mathrm{CI}$ $=4.815$ to 1.025$), 60 \mathrm{mins}(8.740 \mathrm{mmol} / \mathrm{l}$ vs. $5.714 \mathrm{mmol} / \mathrm{l} ; \mathrm{P}=0.0173 ; 95 \% \mathrm{CI}=5.395$ to $0 . .6564)$ and $90 \mathrm{minutes}(9.683 \mathrm{mmol} / \mathrm{l}$ vs. $6.633 \mathrm{mmol} / 1 ; \mathrm{p}=0.0067 ; 95 \% \mathrm{CI}=5.097$ to 1.003$)$.

In summary, Bdnf NTS knockdown mice showed an increase in lean mass without altering physical activity. Illustrating the metabolic benefit of this change in body composition, glucose- and insulin- tolerance tests showed an improved blood glucose handling and disposal and insulin sensitivity in Bdnf NTS knockdown mice.

\section{Acknowledgments}

The authors wish to acknowledge funding from the BBSRC (BBN017838/1).

\section{References}

1. Clark C, Hasser E, Kunze D, et al. (2011) J Neurosci, 31(34), pp.12318-12329.

2. Lee J \& Jun H (2019) Front Physio, 10. 